\title{
Role of Ultrasound in Detection of Abruptio Placentae and its Clinical Correlation
}

\author{
Gurung SD ${ }^{1}$, Shrestha $\mathbf{J}^{1}$, Sharma $\mathbf{P}^{2}$ \\ ${ }^{1}$ Department of Obstetrics and Gynecology, Manipal Teaching Hospital, Pokhara, Nepal \\ ${ }^{2}$ Department of Radiology and Imaging, Manipal Teaching Hospital, Pokhara, Nepal
}

Received: October 13, 2018

Accepted: November 10, 2018

Published: December 30, 2018

Cite this paper:

Gurung SD, Shrestha J, Sharma P. Role of ultrasound in detection of abruptio placentae and its clinical correlation. Nepalese Journal of Radiology 2018;8(12):35-39. https://doi.org/10.3126/njr.v8i2.22982

\begin{abstract}
Introduction: Abruptio placentae is one of the major complications in second half of pregnancy. It accounts for $0.4-1 \%$ of all deliveries. With the advent of ultrasonography, though abruptio placentae has been diagnosed however the sensitivity is less. Those patients clinically suspicious of abruption placenta with negative ultrasound findings can have positive intrapartum findings suggestive of abruptio. Fetal outcome is associated with the gestational age. Preterm deliveries with abruption have higher incidence of perinatal morbidity and mortality as compared to term pregnancies.
\end{abstract}

Methods: It is a prospective study conducted in Manipal Teaching Hospital, Pokhara from July 2017 to July 2018. All the cases of more than twenty eight weeks gestation, singleton pregnancies without preexisting maternal medical diseases suspicious of abruption placentae were included in the study. Ultrasonological and intrapartum findings were recorded. Data was analyzed using SPSS (VERSION16).

Results: Out of forty patients presented with per vaginal bleeding, sixteen were diagnosed as placental abruption either clinically or ultrasonographically. Only ten patients had positive ultrasound findings of retroplacental clot or subchorionic hemorrhage. Out of six patients with negative ultrasound findings, only four had positive Intrapartum findings suggestive of abruption placenta. The specificity (100\%) of ultrasound in diagnosing abruption was more than the sensitivity $(71.43 \%)$ and the accuracy was $75 \%$.

Conclusion: Ultrasound is less sensitive in diagnosing abruption placenta and the lesser the gestational age, the more in the increase in perinatal morbidity and mortality.

Key words: Gestational Age; Hemorrhage, Uterine; Premature Birth

\section{INTRODUCTION}

$\overline{\text { Correspondence to: Dr. Sangeeta Devi Gurung }}$

Department of Obstetric and Gynaecology

Manipal Teaching Hospital

Pokhara, Nepal

Email: gurungsangeeta2018@gmail.com
Antepartum hemorrhage is defined as the bleeding from the vagina before the onset of labour. It is one of the leading cause of increase maternal and perinatal mortality 
and morbidity globally. Abruptio placenta is defined as the separation of the placenta from its implantation site before delivery. It is also known as placenta abruption, accidental hemorrhage. The Latin term abruption placenta means "rending asunder of the placenta" and denotes a sudden accident, which is a clinical characteristics of most cases. ${ }^{1}$ Abruption placenta complicates around $0.4-1 \%$ of deliveries and is associated with increased risk of preterm deliveries, IUFD and still birth. ${ }^{2,3,4,5,6}$ The incidence of preterm births associated with abruption placenta may be up to $10 \% .^{2}$ The diagnosis of abruption is usually made clinically. The triad includes abdominal pain, unusual uterine tenderness and vaginal bleeding. The classical hallmark is per vaginal bleeding which may be present in up to $80-90 \%$ of the cases. However, these symptoms may not be present in all the cases.

With the advent of ultrasound, it has been useful in the diagnosis of antepartum hemorrhage. However, in abruption placenta of mild or early stage or in revealed type, where the blood has escaped out of the vagina, no ultrasound findings may be detected. The ultrasound findings of abruption may show retroplacental blood clots, marginal hematoma, subchorionic hematoma. ${ }^{9}$ The purpose of this study was to estimate the sensitivity, specificity and accuracy of ultrasound in the diagnosis of placental abruption and its clinical correlation with fetomaternal outcome.

\section{METHODS}

This is a prospective study which was carried out in the obstetrics department of Manipal Teaching Hospital, Pokhara, for a period of one year from July 2017 to July 2018. All pregnant women beyond 28 weeks of gestation presented in the emergency with suspicious of abruption placenta were included in the study. All women beyond 28 weeks of gestation with vaginal bleeding were sent for ultrasonography and those detected with abruption were included in the study. However, those with negative radiological findings of abruption but clinically suspected as they had uterine tenderness associated with vaginal bleeding were included in the study. All those pregnant ladies with per vaginal bleeding but ultrasonologically diagnosed of placenta previa, those with gestational age less than 28 weeks, multiple pregnancies and preexisting medical illness of the mother were excluded from the study.

Out of forty pregnant ladies beyond twenty eight weeks gestation with singleton pregnancies without preexisting medical problems who presented in the emergency with history of per vaginal bleeding, only sixteen were diagnosed with abruptio placentae either ultrasonologically or clinically. Positive sonographic findings were defined as presence of retroplacental blood clot or subchorionic hematoma. Negative radiological findings but clinical findings of per vaginal bleeding, uterine tenderness, and abnormal fetal heart sound after exclusion of placenta previa and local causes and by examination of placenta showing depression in the maternal side of the placenta after were included in the study. Data were collected and then sensitivity, specificity, accuracy of the ultrasound was calculated using SPSS version 16 and were correlated clinically.

\section{RESULTS}

During the study period from July 2017 to July 2018 there were 2769 deliveries. Only sixteen patients were diagnosed abruption clinically or radiologically. This showed that the incidence of abruption was $0.58 \%$ $(n=16)$. Out of sixteen pregnant ladies who presented in the emergency with the history of per vaginal bleeding, only ten patients had positive ultrasonological findings of abruption showing subchorionic hemorrhage or retroplacental blood clots. In six patients, there were negative ultrasonological findings. Out of these six patients, four had positive intraoperative findings suggestive of abruption placentae. All of the four patients had blood mixed liquor and one had couvelliere uterus. The two patients who were suspected clinically of abruption placentae but with negative ultrasonographic findings had no evidence of abruption intrapartum. As 
there was irregular heart sound and tonic and tender uterine contraction with per vaginal bleeding, these two patients were undergone cesarean section for good fetal outcome (Table 1). The sensitivity of ultrasound in detecting abruption was $71.43 \%$ (CI 41.90\% - 91.61\%), specificity was 100\% (CI 15.81\%-100\%) and accuracy was $75 \%$ (CI $47.62 \%-92.73 \%$ ) as shown in Table 2.

Out of sixteen patients, three were less than thirty four weeks gestation, six were between thirty four and thirty seven weeks gestation and seven were more than thirty seven weeks of gestation. In this study, there were two intrauterine fetal deaths and two were still births. All these four cases were less than thirty four weeks of gestation. Six babies needed admission in neonatal intensive care unit but there were no neonatal death recorded as this may be due to early detection and intervention for the good perinatal outcome. All the patients beyond thirty four weeks of gestation underwent cesarean section and only two of less than thirty two weeks of gestation had vaginal delivery as they had come in active stage of labour with absent fetal heart sound. However, ultrasound was done to confirm the viability of the fetus which showed evidence of retroplacental blood clots and absent fetal heart sound. One patient had couvelaire uterus (Table 3).

\section{Table 1: Ultrasound and Intrapartum findings of abruption placentae}

\begin{tabular}{l|c|c|}
\multirow{2}{*}{$\begin{array}{l}\text { Ultrasound } \\
\text { findings }\end{array}$} & \multicolumn{2}{|c|}{ Intrapartum findings } \\
\cline { 2 - 3 } & Present & Absent \\
\hline Present & 10 & 0 \\
\hline Absent & 4 & 2 \\
\hline
\end{tabular}

Table 2: Sensitivity, specificity and accuracy

\begin{tabular}{|l|l|l|}
\multicolumn{2}{c|}{ of ultrasound } \\
\cline { 3 - 3 } Sensitivity & $71.43 \%$ & $95 \% \mathrm{CI}$ \\
& & $91.90 \%-$ \\
& & $91.61 \%$ \\
\hline Specificity & $100 \%$ & $15.81 \%-$ \\
& & $100 \%$ \\
\hline Accuracy & $75 \%$ & $47.62 \%-$ \\
& & $92.73 \%$ \\
\hline
\end{tabular}

Table 3: Clinical correlation with fetal outcome

\begin{tabular}{|l|l|l|l|l|}
\hline Gestational age & & IUFD & Still birth & NICU admission \\
\hline$<34$ weeks & 4 & 2 & 2 & \\
\hline $34-37$ weeks & 6 & & & 4 \\
\hline$>34$ weeks & 6 & & & 2 \\
\hline
\end{tabular}

\section{DISCUSSION}

Abruptio placentae is one of the major cause of vaginal bleeding in second half of pregnancy. This study is conducted to diagnose abruption ultrasonographically and its clinical correlation. The incidence of abruption in this study is $0.58 \%$. Several studies have shown the incidence of abruption to be $1 \% .^{1,10,11}$

Due to the advancement in the radiological machines, diseases have been diagnosed earlier but despite these improvements, the radiological sensitivity in the diagnosis of abruption has not been improved since the last two decades. Only 1 out of 9 cases showed positive sonograms findings of abruption. ${ }^{12}$
This study showed that ultrasound has specificity than sensitivity $(100 \%$ versus $71.43 \%$ ) with accuracy of $75 \%$ in detecting abruption placenta.

This is consistent with the study done by Shinde et a ${ }^{13}$ which showed that USG has low sensitivity but high specificity (57\% versus $100 \%$ ) in detecting abruption. Similarly the study conducted by Glantz et $\mathrm{al}^{11}$ also showed that USG has low sensitivity but high specificity (24\% and $96 \%$ respectively). However, study conducted by Yeo and colleagues $^{14}$ had sensitivity of $80 \%$ and specificity of $92 \%$. Thus, this showed that half of the cases were missed in ultrasound. 
However, negative ultrasound findings will not rule out abruption. In our study a $25 \%$ cases (4 out of 16) had negative ultrasound findings but positive Intrapartum findings suggestive of abruption placentae. This is similar to the study conducted by Sholl ${ }^{15}$ which showed that sonographic evidence of retroplacental clot suggesting abruption were seen only in $25 \%$ of the cases. Similarly, Jaffe et $\mathrm{al}^{12}$ showed positive ultrasound findings in $50 \%$ of the cases.

The fetal outcome depends on the gestational age. The risk to the fetus depends on both the gestational age and the degree of abruption. ${ }^{3}$ Preterm fetus with positive findings in USG suggestive of abruption has poor outcome as compared to term fetus. This is consistent with the study done by Shinde et $\mathrm{al}^{13}$ where seven patients out of sixteen were preterm and had IUFD/stillbirth babies. Similarly, a population based cohort study of 7,508,655 pregnancies conducted in US, showed a perinatal mortality rate of 119 per 1,000 live births among pregnancies complicated with abruption placentae and this increased perinatal mortality was likely because one half of the delivery was preterm. ${ }^{3}$ In our study, there were two IUFDs and two stillbirths and all were less than thirty four weeks gestations. Six neonates needed NICU admission but all were more than thirty four weeks gestations. However, there was no neonatal deaths.

\section{CONCLUSION}

This study showed that the specificity of the ultrasound in detection of abruption placenta was more than its sensitivity. In cases of negative sonographic findings but strong clinical suspicious of abruption, timely intervention in delivery will decrease the perinatal morbidity and mortality. However, the lesser the gestational period more will be the perinatal morbidity and mortality.

\section{CONFLICT OF INTEREST}

None

\section{SOURCES OF FUNDING}

None

\section{REFERENCES}

1. Cunningham FG, Leveno KJ, Bloom SL et al. Williams Obstetrics. $23^{\text {rd }}$ ed. Chapt 35 .

2. Ananth CV, Berkowitz GS, Savitz DA, Lapinski RH. Placental abruption and adverse perinatal outcomes. JAMA 1999;282(17);1646-1651. https://doi.org/10.1001/jama.282.17.1646

3. Ananth CV, Wilcox AJ. Placental Abruption and Perinatal Mortality in the United States. Amer Jrnl of Epidemiology 2001;153(4):332-337. https://doi.org/10.1093/aje/153.4.332

4. Sheiner E, Shoham-Vardi I, Hallak $M$ et al. Placental Abruption in term pregnancies:clinical significance and obstetric risk factors. J Maternal Fetal Neonatal Med 2003;13(1):45-49. https://doi.org/10.1080/jmf.13.1.45.49

5. Salihu HM, Bekan B, Aliyu MH, Rouse DJ, Kirby RS, Alexander GR. Perinatal mortality associated with abruption placenta in singletons and multiples. $\mathrm{Am}$ J Obstet Gynecol 2005;193(1):198-203. https://doi.org/10.1016/j. ajog.2005.05.021

6. Ananth CV, Oyelese Y, Yeo L, Pradhan A, Vintzileos AM. Placental abruption in the United States, 1979 through2001:temporal trends and potential determinants. Am J Obstet Gynecol 2005;192(1):191-198. https://doi.org/10.1016/j. ajog.2004.05.087

7. Rasmussen S,IrgensLM,BergsjøP,Dalaker $\mathrm{K}$. The occurrence of placenta abruption in Norway 1967-1991. Acta Obstet Gynecol Scand 1996;75(3):222-228.


org/10.3109/00016349609047091 
8. Yeo L, Anath CV, Vintzileos A. Placental abruption. Glob Libr Women's Med 2008;ISSN 1756-2228.

9. Oyelese Y. Anath CV. Placental abruption. $J$ Am Obstet Gynecol $2006 ; 108$ (4): $1005-1016$. https://doi.org/10.1097/01. AOG.0000239439.04364.9a

10. Bhide A, Arunkumaran S, Damania KR et al. Practial guide to high risk pregnancy and delivery. A south Asian Perspective. $4^{\text {th }}$ ed. Chapt 10. Elsevier 2015.p.151-162.

11. Glantz C, Pumell L. Clinical Utility of Sonography in the Diagnosis and Treatment of Placental Abruption. $J$ Ultrasound Med 2002;21(8):837-840. https://doi.org/10.7863/ jum.2002.21.8.837

12. Jaffe MH, Schoen WC, Silver TM, Bowerman RA, Stuck KJ. Sonography of abruption placentae. AJR Am J Roentgenol 1981;137(5):1049-1054. https://doi.org/10.2214/ajr.137.5.1049
13. Shinde GR, Vaswani BP, Patange RP, Laddad MM, Bhosale RB. Diagnostic Perfomance of Ultrasonography for Detection of Abruption and Its Clinical Correlation and Maternal and Foetal Outcome. $J$ Clin Diagn Res 2016;10(8):QCO4-QCO7. https://dx.doi.org/10.7860\%2FJCDR \%2F 2016\%2F 19247.8288

14. Yeo L, Ananth CV, Vintzileos A. Placental Abruption. In: Sciarra J, editor. Gynaecology and obstetrics. Hagerstown (MD). Lippincott: Williams and Wilkins;2004

15. Scholl JS. Abruptio placentae: clinical management in nonacute cases. $\mathrm{Am} J$ Obstet Gynecol 1987;156(1):40-51. https://doi.org/10.1016/00029378(87)90200-6 